\title{
Fontes e doses de nitrogênio na produtividade do capim-Marandu ${ }^{1}$
}

Jussara Maria dos Santos Cardoso ${ }^{2}$, Alex Carvalho Andrade ${ }^{3}$, João Avelar Magalhães ${ }^{4}$, Braz Henrique Nunes Rodrigues ${ }^{4}$, Johnston Silva Vieira ${ }^{5}$, Fabíola Helena dos Santos Fogaça ${ }^{4}$, Herony Ulisses Mehl ${ }^{4}$, Newton de Lucena Costa ${ }^{6}$

\author{
${ }^{1,2}$ Parte da Monografia apresentada pelo primeiro autor à UESPI, como requisito parcial para obtenção do \\ título de Engenheiro Agrônomo. \\ ${ }^{3}$ Professor do Curso de Agronomia/UESPI. Parnaíba, PI. \\ ${ }^{4}$ Pesquisadores da Embrapa Meio-Norte. Parnaíba, PI. \\ ${ }^{5}$ Mestrando em Agronomia/UFPI. Teresina, PI. \\ ${ }^{6}$ Pesquisador da Embrapa Roraima. Boa Vista, RR. \\ *Autor para correspondência, E-mail: jussaracardoso_agro@hotmail.com
}

\begin{abstract}
RESUMO. Objetivou-se com este trabalho avaliar a resposta de fontes e doses de nitrogênio na produtividade do capim Brachiaria brizantha cv. Marandu nas condições edafoclimáticas dos Tabuleiros Costeiros do Piauí. O trabalho foi conduzido à campo, no período de maio à julho de 2013, no Campo Experimental da Embrapa Meio-Norte, localizado no município de Parnaíba, Piauí. Os tratamentos foram constituídos da combinação de duas fontes de nitrogênio (sulfato de amônio e ureia) e três níveis de nitrogênio 19,56; 39,12 e 58,68 kg/ha/corte correspondendo a $170,340,510 \mathrm{~kg} / \mathrm{ha} / \mathrm{ano}$, segundo o delineamento em blocos ao acaso com três repetições. Foram realizados três cortes com intervalo de 42 dias. A adubação nitrogenada influenciou positivamente a produtividade de matéria seca total. A relação folha/colmo e a eficiência de utilização do nitrogênio responderam de forma negativa aos incrementos do nitrogênio.
\end{abstract}

Palavras chave: Eficiência do uso do nitrogênio, relação folha-colmo, sulfato de amônio, ureia

\section{Sources and doses of nitrogen in the productivity of Marandu-grass}

\begin{abstract}
The objective of this study was to evaluate the response of sources and levels of nitrogen on productivity of Brachiaria brizantha. Marandu at conditions of the Coastal Table lands of Piaui. The work was conducted to field, from May to July 2013 at the Experimental Station of Embrapa Meio-Norte, located in the city of Parnaíba, Piauí. The treatments consisted of the combination of two nitrogen sources (ammonium sulphate and urea) and three levels of nitrogen 19.56; 39.12 and $58.68 \mathrm{~kg} / \mathrm{ha} / \mathrm{cut}$ corresponding to $170,340,510 \mathrm{~kg} / \mathrm{ha} /$ year, according to the randomized complete block design with three replications. Three cuts with an interval of 42 days each. Nitrogen fertilization positively influenced the yield of total dry matter. Leaf/stem ratio and the efficiency of nitrogen utilization responded negatively to increases nitrogen.
\end{abstract}

Keywords: Ammonium sulfate, efficiency of nitrogen use, leaf-stem, urea

\section{Introdução}

As pastagens representam a fração mais econômica que compõe a alimentação dos bovinos e, como tal, constituem a base de sustentação da atividade pecuária nos trópicos. Cerca de $80 \%$ das áreas de pastagens cultivadas no Brasil são ocupadas por genótipos de Brachiaria, com a Brachiaria brizantha cv. Marandu (capim-Marandu) representando 50\% deste total. Em algumas regiões é a espécie forrageira mais importante para a alimentação dos bovinos de corte e/ou leite. Em geral, a produtividade do capim-Marandu é bastante elevada, no entanto, pode ser afetada pelas condições do solo e clima, densidade de plantio, espaçamento e manejo. Segundo Costa et al. (1993), as produções de matéria seca do capimMarandu estão em torno de 10 a 12 t/ha, no período chuvoso, e 2 a $4 \mathrm{t} / \mathrm{ha}$, durante o período 
seco. O valor nutritivo é considerado entre moderado e bom, considerando-se consumo, digestibilidade e composição química. Com duas a seis semanas de rebrote, apresenta em média, digestibilidade da matéria seca entre 65 e 72\%; teores de proteína bruta entre 7 e $15 \%$; teores de fósforo de 0,15 a $0,17 \%$ e de cálcio entre 0,14 e $0,22 \%$.

Por outro lado, um dos fatores limitante na produtividade das pastagens é a adubação, principalmente a nitrogenada. A reposição do nitrogênio é essencial para o aumento da longevidade das pastagens e aumento na produtividade (Costa, 2004). O nitrogênio é um dos nutrientes mais exigidos pelas plantas e um dos mais utilizados na fertilização agrícola (Garcia et al., 1996, Salazar, 2004). Para Jarvis et al. (1995), a aplicação de nitrogênio é considerada fator chave para o de manejo de pastagens e para a obtenção de índices elevados de produtividade. O nitrogênio é o principal constituinte das proteínas que participam ativamente na síntese dos compostos orgânicos que formam a estrutura do vegetal, com elevada influencia sobre as características morfogênicas e estruturais das plantas (Costa et al., 2006).

A ureia e o sulfato de amônio são as fontes nitrogenadas mais utilizadas na agricultura brasileira, possivelmente pelo menor custo e a maior disponibilidade no mercado. Ambas apresentam baixa eficiência de utilização pelas culturas, raramente superior a 50\%. A ureia, pelas suas características e reação no solo, possui grande potencial de perda de $\mathrm{NH}_{3}$ por volatilização, e o sulfato de amônio, além da possibilidade de perda, apresenta alta capacidade de acidificar o solo (Arf et al., 2011).

Objetivou-se com este trabalho avaliar a resposta de fontes e doses de nitrogênio na produtividade do capim Brachiaria brizantha $\mathrm{cv}$. Marandu, nas condições edafoclimáticas de Parnaíba, Piauí.

\section{Material e Métodos}

O trabalho foi conduzido no Campo Experimental da Embrapa Meio Norte/UEP Parnaíba, no município de Parnaíba-PI (2 ${ }^{\circ} 54^{\prime} 18,89^{\prime}$ 'Sul e $41^{\circ} 466^{\prime} 33,24^{\prime}$ 'Oeste), no período de maio a julho de 2013. O clima da região é do tipo subúmido seco e úmido nos períodos seco e chuvoso, respectivamente. A temperatura média anual está em torno de $28^{\circ} \mathrm{C}$ e a precipitação pluviométrica média anual de aproximadamente $1.000 \mathrm{~mm}$. Os dados climáticos correspondentes ao período do experimento foram obtidos na estação meteorológica do INEMET localizada cerca de $400 \mathrm{~m}$ da área experimental (Figuras 1 e 2).

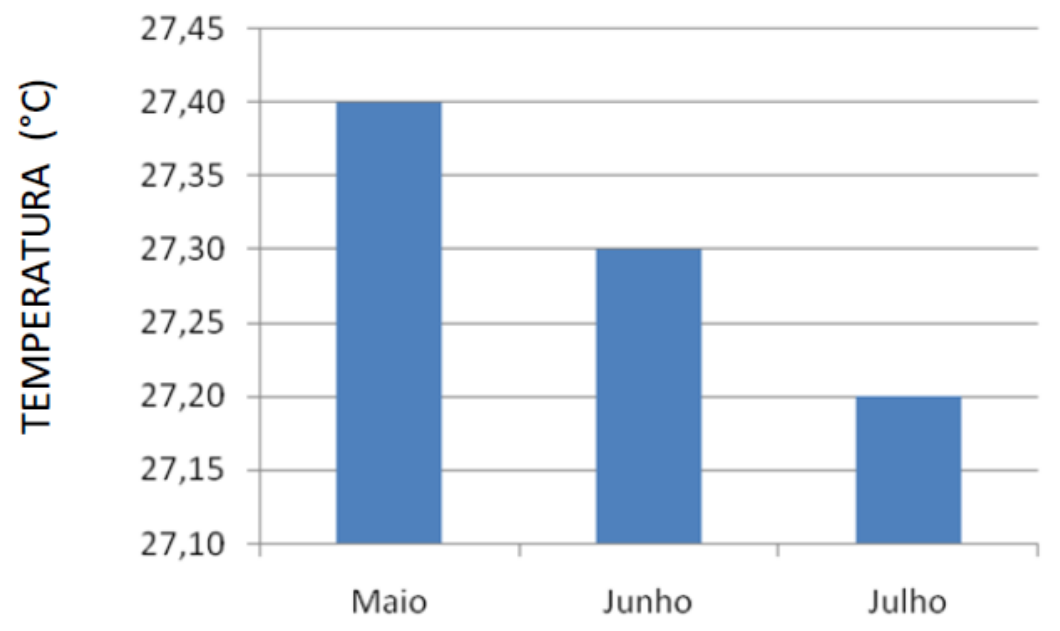

Figura 1. Temperatura média mensal de maio a julho de 2013. Parnaíba, Piauí. 


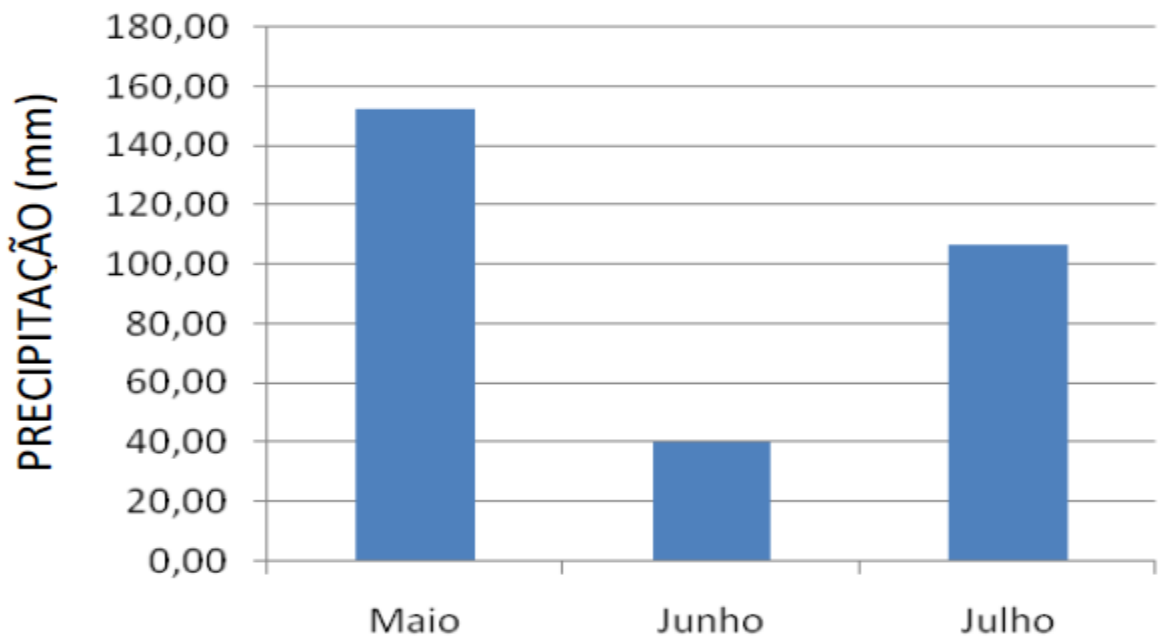

Figura 2. Precipitação mensal de maio a julho de 2013. Parnaíba, Piauí.

O solo da área experimental foi classificado como Latossolo Amarelo Distrófico, textura média, fase caatinga litorânea de relevo plano e suavemente ondulado (Melo et al., 2004), com as seguintes características químicas as seguintes características químicas: $\mathrm{MO}=9,56 \mathrm{~g} / \mathrm{kg}$; $\mathrm{pH}\left(\mathrm{H}_{2} \mathrm{O}\right)=6,92 ; \mathrm{P}=0,30 \mathrm{mg} / \mathrm{dm}^{3} ; \quad \mathrm{K}=$ $0,17 \mathrm{cmol}_{\mathrm{c}} / \mathrm{dm}^{3} ; \mathrm{Ca}=1,91 \mathrm{cmol}_{\mathrm{c}} / \mathrm{dm} 3 ; \mathrm{Mg}=$ $1,91 \mathrm{cmol}_{\mathrm{c}} / \mathrm{dm}^{3} ; \mathrm{Na}=0,08 \mathrm{cmol}_{\mathrm{c}} / \mathrm{dm}^{3} ; \mathrm{Al}=0,01$ $\mathrm{cmol}_{\mathrm{c}} / \mathrm{dm} 3 ; \mathrm{H}+\mathrm{Al}=1,25 \mathrm{cmol}_{\mathrm{c}} / \mathrm{dm}^{3} ; \mathrm{S}=2,85$ $\mathrm{cmol}_{\mathrm{C}} / \mathrm{dm}^{3} ; \mathrm{CTC}=3,91 \mathrm{cmol}_{\mathrm{c}} / \mathrm{dm}^{3} ; \mathrm{V}=87,11 \%$; $\mathrm{m}=0,00 \%$.

$\mathrm{O}$ delineamento experimental foi em blocos ao acaso com três repetições. Os seis tratamentos foram constituídos da combinação de duas fontes de nitrogênio (sulfato de amônio e ureia) e três níveis de $\mathrm{N}(19,56 ; 39,12$ e 58,68 kg/ha.corte, correspondendo a $170,340,510 \mathrm{~kg} / \mathrm{ha}$.ano). As parcelas experimentais mediam $3 \mathrm{~m} \times 3 \mathrm{~m}\left(9 \mathrm{~m}^{2}\right)$, definindo-se uma área útil de $1 \mathrm{~m}$ x $1 \mathrm{~m}$.

Foram realizados três cortes com intervalo de 42 dias na altura de $25 \mathrm{~cm}$ acima do solo, cuja média foi utilizada para a análise estatística. Antes de cada corte era realizada a medição da altura das plantas, com auxílio de uma régua graduada em três diferentes pontos, medindo desde a superfície do solo até a curvatura das folhas superiores. Para medir o nível de luz do local foi utilizado um luxímetro digital portátil. A medição da intensidade da luz foi feita um dia antes de cada corte no período do meio dia, colocando o aparelho em dois níveis, um acima do dossel e o outro ao nível do solo com três repetições na área de cada tratamento.
Após cada corte, todo o material colhido da área útil de cada parcela, foi levado rapidamente para o laboratório dentro de sacos plásticos, onde a massa verde total foi pesada em balança analítica. Retirou-se uma amostra de cada parcela que foi pesada e realizada a separação em lâminas verdes, colmo mais bainha e matéria morta e, posteriormente, levados para a estufa com ventilação forçada por $72 \mathrm{~h}$ à $65^{\circ} \mathrm{C}$, até o peso constante, a fim de obter a estimativa da matéria seca (MS).

As variáveis avaliadas foram: altura das plantas; teor de matéria seca (MS); produtividade de MS total (PMST); produtividade de MS verde (PMSV); produtividade de lâminas foliares (PLF); produtividade de colmos (PC); taxa de acúmulo de matéria seca (TAMS); eficiência do uso do nitrogênio (EUN); relação folha-colmo; relação material vivo/material morto; interceptação e penetração da luz, além da análise econômica dos custos de utilização da adubação nitrogenada.

A taxa de acúmulo diário de MS foi obtida através da razão entre a produção total de MS e o número de dias do período experimental (42 dias). A PMST foi calculada multiplicando-se a taxa de acúmulo diária de MS pelo número de dias entre os cortes (42 dias).

A determinação da eficiência de utilização do $\mathrm{N}$ (kg de MS/kg de N) foi obtida subtraindo-se da produção total de MS ( $\mathrm{kg}$ de MS/ha) de cada tratamento adubado com $\mathrm{N}$, a produção daquele com a menor dose. Essa diferença de produção 
foi dividida pela dose de nitrogênio empregada no respectivo tratamento.

Os dados obtidos foram analisados através do programa Assistat (Silva \& Azevedo, 2002) e submetidos à análise de variância que separou como causa de variação o efeito do fator 1 (fonte de nitrogênio), efeito do fator 2 (doses de $\mathrm{N}$ ) e a interação entre ambos (fonte $\mathrm{x}$ doses).

\section{Resultados e Discussão}

Observou-se interação $(\mathrm{P}<0,05)$ entre fontes e doses de $\mathrm{N}$ para a altura de plantas do capimMarandu (Tabela 1), fato que não se repetiu para as outras variáveis estudadas. Independentemente da fonte utilizada se observou maior altura das plantas na maior dose de $\mathrm{N}(\mathrm{P}<0,05)$ e as plantas adubadas com ureia atingiram maior altura $(\mathrm{P}<0,05)$ que as adubadas com sulfato de amônio (Tabela 1).

Os maiores valores médios da altura das plantas $(113,08$ e $90,36 \mathrm{~cm})$ ocorreram na maior dose, mostrando aumentos de 108,9 e $90,6 \%$ em relação à menor dose para a ureia e sulfato de amônio, respectivamente. Esse resultado é decorrente das funções desempenhadas pelo $\mathrm{N}$, como componente estrutural de macromoléculas e enzimas, envolvidas no processo de desenvolvimento vegetativo das plantas (Malavolta, 2006).

Além disso, no que se refere a animais em condição de pastejo, a profundidade do bocado guarda uma relação positiva com a altura do pasto. À medida que se aumenta a altura do pasto, aumenta-se a massa de forragem, consequentemente a quantidade de forragem disponível para os animais em pastejo (Canto et al., 2002).

Silva et al. (2013) avaliando fontes e doses de $\mathrm{N}$ sobre as características estruturais e produtivas do capim-Marandu, observaram maiores valores médios da altura das plantas na dose de 300 $\mathrm{kg} / \mathrm{ha} / \mathrm{ano}$. Efeitos semelhantes foram observados por Magalhães et al. (2008) quando utilizaram três níveis de $\mathrm{N}$ no capim-elefante $(150 ; 300$ e $450 \mathrm{~kg}$ de N/ha/ano), sendo as maiores alturas obtidas com a aplicação de $450 \mathrm{~kg}$ de N/ha/ano. Belarmino et al. (2003) observaram que a altura das plantas de capim-Tanzânia, submetido a doses de zero a $200 \mathrm{~kg}$ de N/ha/ano, aumentou de forma linear em função da adubação nitrogenada.

Tabela 1. Fontes e doses nitrogênio (N) sobre a altura de plantas do capim-Marandu em Parnaíba, PI. 2013.

\begin{tabular}{lcccc}
\hline & \multicolumn{4}{c}{ Doses de N (kg/há/corte) } \\
\cline { 2 - 4 } Fontes & 19,56 & 39,12 & 58,68 & \\
\cline { 2 - 4 } & \multicolumn{4}{c}{ Cltura $(\mathrm{cm})$} \\
\hline Ureia & $54,13 \mathrm{Ca}$ & $83,17 \mathrm{Ba}$ & $113,08 \mathrm{Aa}$ & 1,98 \\
Sulfato de amônio & $47,40 \mathrm{Cb}$ & $65,57 \mathrm{Bb}$ & $90,36 \mathrm{Ab}$ & \\
\hline
\end{tabular}

Médias seguidas de mesma letra, maiúsculas nas linhas e minúsculas nas colunas, não diferem entre si $(\mathrm{P}>0,05)$ pelo teste de Tukey.

Os teores de MS não foram influenciados pelas fontes de $\mathrm{N}(\mathrm{P}>0,05)$ e na menor dose de $\mathrm{N}$ observou-se maior teor de MS $(\mathrm{P}<0,05)$ em relação às demais (Tabela 2). A redução do teor de MS pode ser explicada pela maior produção de colmos (Tabela 6) em relação às folhas, proporcionada pela adição de adubo, pois o maior teor de umidade encontra-se nas folhas, fato também observado por (Aguiar et al., 2000)

Tabela 2. Fontes e doses nitrogênio (N) sobre os teores de matéria seca (MS) do capim-Marandu em Parnaíba, PI. 2013.

\begin{tabular}{|c|c|c|c|c|c|}
\hline \multirow{3}{*}{ Fontes } & \multicolumn{3}{|c|}{ Doses de N (kg/ha/corte) } & \multirow{3}{*}{ Médias } & \multirow{3}{*}{$\mathrm{CV}(\%)$} \\
\hline & 19,56 & 39,12 & 58,68 & & \\
\hline & \multicolumn{3}{|c|}{ MS (\%) } & & \\
\hline Ureia & 27,69 & 24,75 & 23,97 & $25,47 \mathrm{a}$ & \multirow{2}{*}{5,27} \\
\hline Sulfato de amônio & 26,47 & 24,96 & 23,42 & 24,89 a & \\
\hline Médias & $27,08 \mathrm{~A}$ & $24,86 \mathrm{~B}$ & $23,61 \mathrm{~B}$ & & \\
\hline
\end{tabular}


Observou-se maior PMST e PMSV na maior dose de $\mathrm{N}(\mathrm{P}<0,05)$ e ambas variáveis não foram influenciadas pelas fontes de adubos $(\mathrm{P}>0,05)$ (Tabelas 3 e 4). $\mathrm{O}$ uso do $\mathrm{N}$ propicia maior produção de partes vegetativas das plantas, promovendo maior área fotossintética, com isso, implica maior produtividade de MS e MSV. Segundo Martuscello et al. (2009), o uso de adubos nitrogenados para o aumento na produção de forragem, é algo esperado em experimentos realizados com o $\mathrm{N}$, devido ao seu efeito no acúmulo de matéria seca, pois o uso de $\mathrm{N}$ é um dos fatores de manejo que controla os diferentes processos de crescimento das plantas, consequentemente maior produção de MS. Benettt et al. (2008), trabalhando com doses até $200 \mathrm{~kg} / \mathrm{ha}$ de nitrogênio em $B$. brizantha cv. Marandu, observaram que a produção de MS foi proporcional às doses testadas, fato também observado por Whitney Whitney \& Green (1969) e Byam \& Gumbs (1975).

Tabela 3. Fontes e doses de nitrogênio $(\mathrm{N})$ sobre a produtividade de matéria seca total (PMST) do capimMarandu em Parnaíba, PI. 2013.

\begin{tabular}{|c|c|c|c|c|c|}
\hline \multirow{3}{*}{ Fontes } & \multicolumn{3}{|c|}{ Doses de N (kg/ha/corte) } & \multirow{3}{*}{ Médias } & \multirow{3}{*}{$\mathrm{CV}(\%)$} \\
\hline & 19,56 & 39,12 & 58,68 & & \\
\hline & \multicolumn{3}{|c|}{ PMST (t/ha) } & & \\
\hline Ureia & 2,75 & 2,92 & 3,85 & $3,17 \mathrm{a}$ & \multirow{2}{*}{12,11} \\
\hline Sulfato de amônio & 2,91 & 3,37 & 3,97 & $3,42 \mathrm{a}$ & \\
\hline Médias & $2,83 \mathrm{~B}$ & $3,14 \mathrm{~B}$ & $3,91 \mathrm{~A}$ & & \\
\hline
\end{tabular}

Tabela 4. Fontes e doses de nitrogênio (N) sobre a produtividade de matéria seca verde (PMSV) do capimMarandu em Parnaíba, PI. 2013.

\begin{tabular}{|c|c|c|c|c|c|}
\hline \multirow{3}{*}{ Fontes } & \multicolumn{3}{|c|}{ Doses de N (kg/ha/corte) } & \multirow{3}{*}{ Médias } & \multirow{3}{*}{$\mathrm{CV}(\%)$} \\
\hline & 19,56 & 39,12 & 58,68 & & \\
\hline & \multicolumn{3}{|c|}{ PMSV (t/ha) } & & \\
\hline Ureia & 2,32 & 2,67 & 3,52 & $2,84 \mathrm{a}$ & \multirow{2}{*}{9,10} \\
\hline Sulfato de amônio & 2,52 & 3,00 & 3,62 & $3,05 \mathrm{a}$ & \\
\hline Médias & $2,42 \mathrm{~B}$ & $2,84 \mathrm{~B}$ & $3,57 \mathrm{~A}$ & & \\
\hline
\end{tabular}

Médias seguidas de mesma letra, maiúsculas nas linhas e minúsculas nas colunas, não diferem entre si $(\mathrm{P}>0,05)$ pelo teste de Tukey

A diferença entre a disponibilidade de MST e MSV representa o material senescente e morto que acaba sendo descartado pelo animal. A perda de folhas por senescência pode minimizar a eficiência de colheita por corte ou em pastejo. Castagnara et al. (2011) estudando os efeitos de doses crescentes de $\mathrm{N}$ sobre as gramíneas Panicum maximum cv. Mombaça e Tanzânia, e Brachiaria sp. Mulato, observaram efeito linear positivo das doses de $\mathrm{N}$ sobre a porcentagem de matéria verde.

Na produtividade de lâminas foliares (Tabela 5) e de colmos (Tabela 6), as fontes de $\mathrm{N}$ não diferiram entre si $(\mathrm{P}>0,05)$. Entretanto, a maior dose de $\mathrm{N}$ propiciou maior produtividade de lâmina foliar e de colmo.

A aplicação de $\mathrm{N}$ favoreceu a produção de lâminas foliares, confirmando o rápido efeito do $\mathrm{N}$ em aumentar a taxa fotossintética das plantas e o maior fornecimento de fotoassimilados para os tecidos em crescimento (Teixeira et al., 2011). Os resultados obtidos no experimento estão de acordo com os relatados por Silva et al. (2005) após submeter o capim-Marandu a doses de $\mathrm{N}$ entre 50 e $800 \mathrm{~kg} / \mathrm{ha}$. 
Tabela 5. Fontes e doses de nitrogênio $(\mathrm{N})$ sobre a produtividade de lâminas foliares (PLF) do capim-Marandu em Parnaíba, PI. 2013.

\begin{tabular}{|c|c|c|c|c|c|}
\hline \multirow{3}{*}{ Fontes } & \multicolumn{3}{|c|}{ Doses de $\mathrm{N}(\mathrm{kg} / \mathrm{ha} /$ corte $)$} & \multirow{3}{*}{ Médias } & \multirow{3}{*}{$\mathrm{CV}(\%)$} \\
\hline & 19,56 & 39,12 & 58,68 & & \\
\hline & \multicolumn{3}{|c|}{ PLF (t/ha) } & & \\
\hline Ureia & 1,66 & 1,85 & 2,31 & $1,94 \mathrm{a}$ & \multirow{2}{*}{7,12} \\
\hline Sulfato de amônio & 1,72 & 1,98 & 2,38 & $2,02 \mathrm{a}$ & \\
\hline Médias & $1,69 \mathrm{~B}$ & $1,91 \mathrm{~B}$ & $2,34 \mathrm{~A}$ & & \\
\hline
\end{tabular}

Médias seguidas de mesma letra, maiúsculas nas linhas e minúsculas nas colunas, não diferem entre si $(\mathrm{P}>0,05)$ pelo teste de Tukey.

As folhas verdes é a porção da planta que apresenta maior valor nutritivo e são as preferidas pelos animais. Magalhães (2010) concluiu que a adubação nitrogenada aumenta a produtividade, como também acelera a maturidade da planta, fazendo com que além das folhas o colmo se alongue, acarretando na redução da qualidade da pastagem. Entretanto, a produção de MS de colmos e bainhas é componente relevante para a produção de forragem, pois estas estruturas são armazenadoras de substâncias orgânicas nas gramíneas, o que pode interferir na capacidade de rebrotação dos capins (Silva et al., 2013).

Tabela 6. Fontes e doses de nitrogênio (N) sobre a produtividade de colmos (PC) do capim-Marandu em Parnaíba, PI. 2013.

\begin{tabular}{|c|c|c|c|c|c|}
\hline \multirow{3}{*}{ Fontes } & \multicolumn{3}{|c|}{ Doses de N (kg/ha/corte) } & \multirow{3}{*}{ Médias } & \multirow{3}{*}{$\mathrm{CV}(\%)$} \\
\hline & 19,56 & 39,12 & 58,68 & & \\
\hline & \multicolumn{3}{|c|}{$\mathrm{PC}(\mathrm{t} / \mathrm{ha})$} & & \\
\hline Ureia & 0,66 & 0,82 & 1,21 & $0,90 \mathrm{a}$ & \multirow{2}{*}{15,10} \\
\hline Sulfato de amônio & 0,80 & 1,02 & 1,24 & $1,02 \mathrm{a}$ & \\
\hline Médias & $0,73 \mathrm{~B}$ & $0,92 \mathrm{~B}$ & $1,23 \mathrm{~A}$ & & \\
\hline
\end{tabular}

Médias seguidas de mesma letra, maiúsculas nas linhas e minúsculas nas colunas, não diferem entre si $(\mathrm{P}>0,05)$ pelo teste de Tukey.

A razão folha/colmo do capim-Marandu não foi influenciada $(\mathrm{P}>0,05)$ pelas fontes e doses de N (Tabela 7). De acordo com estudos feitos por Magalhães (2010), maiores produções de colmo nas forrageiras poderão diminuir o valor nutritivo e o aproveitamento da forragem, pois os ruminantes consomem mais folhas em pastejo. Afirma também que a adubação nitrogenada não promove apenas o crescimento de folhas e perfilhos, mas também o dos colmos, ou seja, promove o aceleramento da maturidade das plantas, afetando o consumo dos ruminantes e oferecendo alimento de baixo valor nutritivo.

A razão folha/colmo é uma variável que indica a qualidade das pastagens, pois quanto maior essa relação, melhor para os animais, pois eles possuem o hábito de consumirem preferencialmente as folhas e com isso haverá o maior aproveitamento da pastagem.

Tabela 7. Fontes e doses de nitrogênio (N) sobre a relação folha/colmo do capim-Marandu em Parnaíba, PI. 2013.

\begin{tabular}{|c|c|c|c|c|c|}
\hline \multirow{3}{*}{ Fontes } & \multicolumn{3}{|c|}{ Doses de N (kg/ha/corte) } & \multirow{3}{*}{ Médias } & \multirow{3}{*}{$\mathrm{CV}(\%)$} \\
\hline & 19,56 & 39,12 & 58,68 & & \\
\hline & \multicolumn{3}{|c|}{ Relação folha/colmo } & & \\
\hline Ureia & 2,53 & 2,25 & 1,90 & $2,23 \mathrm{a}$ & \multirow{2}{*}{11,64} \\
\hline Sulfato de amônia & 2,18 & 1,99 & 1,91 & $2,03 \mathrm{a}$ & \\
\hline Médias & $2,36 \mathrm{~A}$ & $2,12 \mathrm{AB}$ & $1,90 \mathrm{~B}$ & & \\
\hline
\end{tabular}

Médias seguidas de mesma letra, maiúsculas nas linhas e minúsculas nas colunas, não diferem entre si $(\mathrm{P}>0,05)$ pelo teste de Tukey 
Observou-se maior TAMS na maior dose de $\mathrm{N} \quad(\mathrm{P}<0,05)$, não havendo diferença $(\mathrm{P}>0,05)$ entre as fontes utilizadas (Tabela 8). O acúmulo de forragem na pastagem após a desfolhação, na ausência de animais, é resultante do fluxo de nova biomassa foliar, definido como crescimento bruto, e do fluxo de substância e decomposição de biomassa foliar mais velha (Hodgson, 1990). Resultado semelhante foi constatado por Fagundes et al. (2006), que relataram o incremento na produção de forragem, ou seja, observou-se aumento nas taxas de acúmulo de forragem com o aumento das doses de N. Lugão et al. (2008) concluíram que as TAMS foram elevadas quando foi utilizada a adubação nitrogenada. Castagnara et al. (2011), avaliando o efeito da adubação nitrogenada sobre a TAMS nas gramíneas Panicum maximum cvs. Mombaça e Tanzânia, e Brachiaria sp. Mulato, constataram que a cada $40 \mathrm{~kg} / \mathrm{ha}$ de $\mathrm{N}$ aplicado tinha-se um acréscimo de $25 \mathrm{~kg} / \mathrm{ha} /$ dia de MS.

Tabela 8. Fontes e doses de nitrogênio (N) sobre a taxa de acumulo de MS (TAMS) do capim-Marandu em Parnaíba, PI. 2013.

\begin{tabular}{|c|c|c|c|c|c|}
\hline \multirow{3}{*}{ Fontes } & \multicolumn{3}{|c|}{ Doses de N (kg/ha/corte) } & \multirow{3}{*}{ Médias } & \multirow{3}{*}{$\mathrm{CV}(\%)$} \\
\hline & 19,56 & 39,12 & 58,68 & & \\
\hline & \multicolumn{3}{|c|}{ TAMS (kg/ha.dia) } & & \\
\hline Ureia & 65,70 & 69,57 & 91,85 & $75,71 \mathrm{a}$ & \multirow{2}{*}{12,11} \\
\hline Sulfato de amônio & 69,30 & 80,37 & 94,71 & $81,46 \mathrm{a}$ & \\
\hline Médias & $67,50 \mathrm{~B}$ & $74,97 \mathrm{~B}$ & $93,28 \mathrm{~A}$ & & \\
\hline
\end{tabular}

Médias seguidas de mesma letra, maiúsculas nas linhas e minúsculas nas colunas, não diferem entre si (P>0,05) pelo teste de Tukey.

$\mathrm{Na}$ menor dose de $\mathrm{N}$ observou-se uma maior eficiência do uso de $\mathrm{N}$ em relação às demais $(\mathrm{P}<0,05)$, não apresentando diferença $(\mathrm{P}>0,05)$ entre as fontes (Tabela 9). Martuscello et al. (2005) e Martuscello et al. (2006) relataram que a maioria dos trabalhos realizados com adubação nitrogenada, mostram respostas positivas conforme o aumento da dose de $\mathrm{N}$ em relação a produção de MS, embora isso não signifique que a maior dose aplicada resulte em maior EUN. Fato comprovado por Dias et al. (1998) que após testar as doses de $0,100,200,400 \mathrm{~kg}$ de N/ha, constataram a maior EUN na dosagem de $100 \mathrm{~kg}$ $\mathrm{N} / \mathrm{ha}$ /dia, onde conforme aumentava a dose de $\mathrm{N}$, havia uma redução na EUN.

A eficiência da adubação nitrogenada pode ser potencializada através da forma foliar, solo e na água de irrigação, como também na época de aplicação e com a fonte de $\mathrm{N}$ utilizada. Porém isso não garante que não haja perdas de $\mathrm{N}$ por volatilização, mas podem ser diminuídas conforme as formas de aplicação e condições de utilização (Alves, 2008). As adubações nitrogenadas, segundo Werner et al. (2001), devem ser parceladas quando se usam doses altas, para evitar as perdas por volatilização e por lixiviação principalmente, buscando a maior eficiência de uso do $\mathrm{N}$.

A relação material vivo/material morto não foi influenciada pelas doses de $\mathrm{N}(\mathrm{P}>0,05)$ não havendo diferença $(\mathrm{P}>0,05)$ entre as fontes utilizadas (Tabela 10). Dados semelhantes foram constatados por Lopes et al. (2007), avaliando as características estruturais de Panicum maximum cv. Aruana, submetido a doses crescentes de N, onde a relação material vivo/material morto não foi afetada $(\mathrm{P}>0,05)$ pelos níveis de $\mathrm{N}$.

Tabela 9. Fontes e doses de nitrogênio (N) sobre a eficiência de uso do nitrogênio (EUN) do capim-Marandu em Parnaíba, PI. 2013.

\begin{tabular}{|c|c|c|c|c|c|}
\hline \multirow{3}{*}{ Fontes } & \multicolumn{3}{|c|}{ Doses de N (kg/ha/corte) } & \multirow{3}{*}{ Médias } & \multirow{3}{*}{$\mathrm{CV}(\%)$} \\
\hline & 19,56 & 39,12 & 58,68 & & \\
\hline & \multicolumn{3}{|c|}{ EUN (kg de MS/kg de N) } & & \\
\hline Ureia & 141,08 & 74,70 & 65,74 & $93,84 \mathrm{a}$ & \multirow{2}{*}{15,83} \\
\hline Sulfato de amônia & 148,81 & 86,28 & 67,79 & $100,96 \mathrm{a}$ & \\
\hline Médias & $144,94 \mathrm{~A}$ & $80,49 \mathrm{~B}$ & $66,76 \mathrm{~B}$ & & \\
\hline
\end{tabular}


Tabela 10. Fontes e doses de nitrogênio (N) sobre a relação material vivo/material morto do capim-Marandu em Parnaíba, PI. 2013.

\begin{tabular}{|c|c|c|c|c|c|}
\hline \multirow{3}{*}{ Fontes } & \multicolumn{3}{|c|}{ Doses de $\mathrm{N}(\mathrm{kg} / \mathrm{ha} /$ corte $)$} & \multirow{3}{*}{ Médias } & \multirow{3}{*}{$\mathrm{CV}(\%)$} \\
\hline & 19,56 & 39,12 & 58,68 & & \\
\hline & \multicolumn{3}{|c|}{ Relação material vivo/material morto } & & \\
\hline Ureia & 7,91 & 11,19 & 10,98 & $10,02 \mathrm{a}$ & \multirow{2}{*}{30,41} \\
\hline Sulfato de amônia & 6,72 & 9,25 & 10,40 & $8,79 \mathrm{a}$ & \\
\hline Médias & $7,31 \mathrm{~A}$ & $10,22 \mathrm{~A}$ & $10,69 \mathrm{~A}$ & & \\
\hline
\end{tabular}

Médias seguidas de mesma letra, maiúsculas nas linhas e minúsculas nas colunas, não diferem entre si $(\mathrm{P}>0,05)$ pelo teste de Tukey.

Fagundes et al. (2006), avaliando o efeito da adubação nitrogenada sobre as características morfogênicas e estruturais de Brachiaria decumbens sob pastejo, utilizando doses crescentes de $\mathrm{N}$, concluíram que a porcentagem de matéria morta decresceu com a adubação nitrogenada. Rodrigues et al. (2009) ressaltam a importância do material morto na pastagem, o qual mantém a umidade do solo e o controle da erosão, afirmando também que a quantidade de nutrientes que pode retornar ao sistema por meio do material morto, vai depender da sua composição e quantidade.

As plantas adubadas com a menor dose de $\mathrm{N}$ já interceptaram 95\% da luz incidente (Tabela 11), valor considerado desejável para obtenção de máxima taxa de acúmulo de forragem (Parsons et al., 1988).

Tabela 11. Fontes e doses de nitrogênio (N) sobre a interceptação da luz (\%) pelo capim-Marandu em Parnaíba, PI. 2013.

\begin{tabular}{|c|c|c|c|c|c|}
\hline \multirow{3}{*}{ Fontes } & \multicolumn{3}{|c|}{ Doses de $\mathrm{N}$ ( $\mathrm{kg} / \mathrm{ha} /$ corte $)$} & \multirow{3}{*}{ Médias } & \multirow{3}{*}{$\mathrm{CV}(\%)$} \\
\hline & 19,56 & 39,12 & 58,68 & & \\
\hline & \multicolumn{3}{|c|}{ Interceptação da luz (\%) } & & \\
\hline Ureia & 96,41 & 96,01 & 96,55 & $96,32 \mathrm{a}$ & \multirow{2}{*}{0,81} \\
\hline Sulfato de amônia & 95,47 & 95,79 & 96,12 & $95,79 \mathrm{a}$ & \\
\hline Médias & $95,94 \mathrm{~A}$ & $95,90 \mathrm{~A}$ & $96,34 \mathrm{~A}$ & & \\
\hline
\end{tabular}

Médias seguidas de mesma letra, maiúsculas nas linhas e minúsculas nas colunas, não diferem entre si $(\mathrm{P}>0,05)$ pelo teste de Tukey.

Por outro lado, uma maior produtividade de folhas, colmos e, consequentemente de MST representa a possibilidade de maior carga animal por área. Até certo ponto, quanto maior for a área foliar, maior será a superfície de exposição das folhas e, portanto, maior interceptação de luz e a capacidade fotossintética da planta o que, provavelmente, refletirá em uma maior capacidade produtiva da pastagem. A penetração de luz não foi influenciada $(\mathrm{P}>0,05)$ pela adubação nitrogenada, como também, pelas fontes de $\mathrm{N}$ (Tabela 12).

Tabela 12. Fontes e doses de nitrogênio (N) sobre a penetração de luz (\%) em capim-Marandu em Parnaíba, PI. 2013.

\begin{tabular}{|c|c|c|c|c|c|}
\hline \multirow{3}{*}{ Fontes } & \multicolumn{3}{|c|}{ Doses de $\mathrm{N}$ (kg/ha/corte) } & \multirow{3}{*}{ Médias } & \multirow{3}{*}{$\mathrm{CV}(\%)$} \\
\hline & 19,56 & 39,12 & 58,68 & & \\
\hline & \multicolumn{3}{|c|}{ Penetração de luz (\%) } & & \\
\hline Ureia & 3,58 & 3,98 & 3,44 & $3,67 \mathrm{a}$ & \multirow{2}{*}{19,70} \\
\hline Sulfato de amônio & 4,52 & 4,20 & 3,87 & $4,20 \mathrm{a}$ & \\
\hline Médias & $4,05 \mathrm{~A}$ & $4,09 \mathrm{~A}$ & $3,65 \mathrm{~A}$ & & \\
\hline
\end{tabular}


A produção da forrageira depende da eficiência do uso da energia fornecida pela luz, ou seja, a taxa fotossintética é um fator limitante na produtividade. A fonte de energia influencia diretamente no crescimento e desenvolvimento das plantas.

Em relação à análise de custo das fontes, a ureia se destaca $(\mathrm{P}>0,05)$ como a mais econômica
(Tabela 13). A ureia predomina como fonte de $\mathrm{N}$ que apresenta menor relação custo/unidade de nutriente e baixa corrosividade (Cabezas et al., 2000, Sangoi et al., 2003). Primavesi et al. (2004) afirmaram que a ureia é de fácil manipulação e causa menor acidificação no solo, apresentando alta concentração de $\mathrm{N}$, tornando o pasto de vista econômico, superior a outras fontes de $\mathrm{N}$.

Tabela 13. Fontes e doses de adubos nitrogenados nos custo de produção de matéria seca do capim-Marandu em Parnaíba, PI. 2013.

\begin{tabular}{|c|c|c|c|c|}
\hline \multirow{3}{*}{ Fontes } & \multicolumn{3}{|c|}{ Doses de N (kg/ha/corte) } & \multirow{3}{*}{$\mathrm{CV}(\%)$} \\
\hline & 19,56 & 39,12 & 58,68 & \\
\hline & \multicolumn{3}{|c|}{ Análise de custo da $t$ de MS (R\$/t) } & \\
\hline Ureia & $6,57 \mathrm{Bb}$ & $11,92 \mathrm{Ab}$ & $13,54 \mathrm{Ab}$ & 12,77 \\
\hline Sulfato de amônio & $16,02 \mathrm{Ca}$ & $27,92 \mathrm{Ba}$ & $35,33 \mathrm{Aa}$ & \\
\hline
\end{tabular}

Médias seguidas de mesma letra, maiúsculas nas linhas e minúsculas nas colunas, não diferem entre si $(\mathrm{P}>0,05)$ pelo teste de Tukey.

Quando a ureia é comparada por unidade de N, se destaca pela facilidade de acesso no mercado e pelo menor custo. Quando aplicada é rapidamente hidrolisada em dois ou três dias. De acordo com mesmo autor, a adubação nitrogenada é bastante onerosa, fazendo-se necessário o uso de fontes que apresentem menor susceptibilidade a perdas por volatilização. O sulfato de amônio se destaca por ser menos sujeito a perdas por volatilização em solos ácidos.

O uso do sulfato de amônio se apresenta no solo como desvantagem, pois é uma reação fortemente ácida, além de possuir apenas $21 \%$ de $\mathrm{N}$, aumentando o custo de aplicação e transporte, sendo maior do que a ureia quanto em relação ao custo por unidade de $\mathrm{N}$.

$\mathrm{Na}$ escolha do adubo nitrogenado a ser utilizado em cobertura na pastagem, deve-se levar em conta além do preço por quilograma de $\mathrm{N}$, do custo de aplicação, do transporte e entre outros custos, as possíveis perdas de $\mathrm{N}$.

\section{Conclusões}

A produtividade de matéria seca total aumenta com a dosagem de nitrogênio em ambas as fontes. A dose de $510 \mathrm{~kg}$ de N/ha/dia proporciona maior rendimento de forragem.

A adubação nitrogenada influencia positivamente a altura das plantas, ao mesmo tempo promove a diminuição dos teores de matéria seca e a redução na relação folha/colmo.
A eficiência de utilização do nitrogênio foi inversamente proporcional ao aumento da dose.

A ureia apresenta melhor retorno econômico em relação ao sulfato de amônio.

\section{Referências Bibliográficas}

Aguiar, R.S., Vasquez, H.M. \& Silva, J.F.C. 2000. Produção e composição químicobromatológica do capim-furachão (Panicum repens $\mathrm{L}$.) sob adubação e diferentes idades de corte. Revista Brasileira de Zootecnia, 29, 325-333.

Alves, A.U., Oliveira, A.P., Alves, E.U., Oliveira, A.N.P., Cardoso, E. de A. \& Matos, B.F. 2009. Manejo da adubação nitrogenada para batata-doce: fontes e parcelamento de aplicação. Ciência Agrotécnica, 33, 15541559.

Arf, M.V., Buzetti, S., Arf, O., Kappes, C., Ferreira, J.P., Gitti, D. \& Yamamoto, C.J.T. 2011. Fontes e épocas de aplicação de nitrogênio em feijoeiro de inverno sob sistema plantio direto. Pesquisa Agropecuária Tropical, 41, 430-438.

Belarmino, M.C.J., Pinto, J.C., Rocha, G.P., Furtini Neto, A.E. \& Morais, A.R. 2003. Altura de perfilho e rendimento de matéria seca de capim Tanzânia em função de diferentes doses de superfosfato simples e sulfato de amônio. Ciência e Agrotecnologia, $27,879-885$. 
Benettt, C.G.S., Yamashita, O.M., Koga, P.S. \& Silva, K.S. 2008. Resposta da Brachiaria brizantha cv. Marandu a diferentes tipos de adubação. Revista de Ciências AgroAmbientais, 6, 13-20.

Byam, L. \& Gumbs, F.A. 1975. Effect of irrigation and nitrogen on the dry matter and crude protein yields of 'Pangola' digitgrass. Agronomy Journal, 67, 365-369.

Cabezas, W.A.R., Trivelin, P.C.O., Kondörfer, G.H. \& Pereira, S. 2000. Balanço da adubação nitrogenada sólida e fluida de cobertura na cultura de milho, em sistema plantio direto no Triângulo Mineiro (MG). Revista Brasileira de Ciência do Solo, 24, 363-376.

Canto, M.W., Cecato, U., Almeida Júnior, J., Jobim, C.C., Agulhon, R.A., Gai, V.F., Hoeschl, A.R. \& Queiroz, M.F.S. 2002. Produção animal no inverno em capim Tanzânia diferido no outono e manejado em diferentes alturas de pasto. Revista Brasileira de Zootecnia, 31, 1624-1633.

Castagnara, D.D., Zoz, T., Krutzmann, A., Uhlein, A., Mesquita, E.E., Neres, M.A. \& Oliveira, P.S.R. 2011. Produção de forragem, características estruturais e eficiência de utilização do nitrogênio em forrageiras tropicais sob adubação nitrogenada. Semina: Ciências Agrárias, 32, 1637-1648.

Costa, N.L. 2004. Formação, manejo e recuperação de pastagens em Rondônia. Porto Velho: Embrapa Rondônia, 224p.

Costa, N.L., Oliveira, J.R.C. \& Paulino, V.T. 1993. Efeito do diferimento sobre o rendimento de forragem e composição química de Brachiaria brizantha cv. Marandu em Rondônia. Revista da Sociedade Brasileira de Zootecnia, 22, 495-510.

Costa, N.L., Paulino, V.T. \& Magalhães, J.A. 2006. Produção de forragem, composição química e morfogênese de Panicum maximum cv. Vencedor sob diferentes níveis de adubação nitrogenada. Revista Científica de Produção Animal, 8, 66-72.

Dias, P.F., Rocha, G.P., Oliveira, A.I.G., Pinto, J.C., Rocha Filho, R.R. \& Souto, S.M. 1998. Produtividade e qualidade de gramíneas forrageiras tropicais sob adubação nitrogenada no final do período das águas. Pesquisa Agropecuária Brasileira, 33, 1191-1197.
Fagundes, J.L., Fonseca, D., Mistura, C., Morais, R., Vitor, C.M.T., Gomide, J.A., Nascimento Junior, D., Casagrande, D. R. \& Costa, L. 2006. Características morfogênicas e estruturais do capim-braquiária em pastagem adubada com nitrogênio avaliadas nas quatro estações do ano. Revista Brasileira de Zootecnia, 35, 21-29.

Garcia, G.W., Ferguson, T.U., Neckles, F.A. \& Archibald, K.A.E. 1996. The nutritive value and forage productivity of Leucaena leucocephala. Animal Feed Science and Technology, 60, 29-41.

Hodgson, J. 1990. Grazing management. Science into practice. Harlow: Longman Scientific \& Technical. 203p.

Jarvis, A.M., Selkirk, L. \& Cockram, M.S. 1995. The influence of source, sex class and preslaughter handling on the bruising of cattle at two slaughterhouses. Livestock Production Science, 43, 215-224.

Lopes, M.N., Pompeu, R.C.F.F., Cândido, M.J.D., Gomes, F.H.T. \& Aquino, B.F. 2007 Efeito da adubação nitrogenada sobre as características morfogênicas de capim-aruana manejada sob corte. In: Reunião Anual da Sociedade Brasileira de Zootecnia, 44, Anais... Jaboticabal: p.1-3.

Lugão, S.M.B., Andrade Rodrigues, L.R., Santos Abrahão, J.J., Malheiros, E.B. \& Morais, A. 2008. Acúmulo de forragem e eficiência de utilização do nitrogênio em pastagens de Panicum maximum Jacq.(Acesso BRA006998) adubadas com nitrogênio. Acta Scientiarum. Animal Sciences, 25, 371-379.

Magalhães, J.A., Lopes, E.A., Rodrigues, B.H.N., Lucena Costa, N., Barros, N.N. \& Mattei, D. A. 2008. Influência da adubação nitrogenada e da idade de corte sobre o rendimento forrageiro do capim-elefante. Revista Ciência Agronômica, 37, 91-96.

Magalhães, J.A. 2010. Características morfogênicas e estruturais, produção e composição bromatológica de gramíneas forrageiras sob irrigação e adubação. Tese, Universidade Federal do Ceará, Fortaleza, $138 \mathrm{f}$.

Malavolta, E. 2006. Manual de nutrição mineral de plantas. Agronômica Ceres, São Paulo.

Martuscello, J.A., Fonseca, D., Nascimento Júnior, D., Santos, P., Ribeiro Júnior, J., 
Cunha, D. \& Moreira, L.d.M. 2005. Características morfogênicas e estruturais do capim-xaraés submetido à adubação nitrogenada e desfolhação. Revista Brasileira de Zootecnia, 34, 1475-1482.

Martuscello, J.A., Fonseca, D.M., Nascimento Júnior, D., Santos, P.M., Cunha, D.N.F.V. \& Moreira, L.M. 2006. Características morfogênicas e estruturais de capim-massai submetido a adubação nitrogenada e desfolhação. Revista Brasileira de Zootecnia, 35, 665-671.

Martuscello, J.A., Jank, L., Gontijo Neto, M.M., Laura, V.A. \& Cunha, D.N.F.V. 2009. Produção de gramíneas do gênero Brachiaria sob níveis de sombreamento. Revista Brasileira de Zootecnia, 38, 1183-1190.

Melo, F.B., Cavalcante, A.C., Andrade Júnior, A.S., Bastos, E.A. 2004. Levantamento detalhado dos solos da área da Embrapa Meio-Norte/UEP de Parnaíba. Embrapa MeioNorte. 26p. (Documentos, 89).

Parsons, A.J., Johnson, I. \& Harvey, A. 1988. Use of a model to optimize the interaction between frequency and severity of intermittent defoliation and to provide a fundamental comparison of the continuous and intermittent defoliation of grass. Grass and Forage Science, 43, 49-59.

Primavesi, A.C., Primavesi, O., Corrêa, L.A., Cantarella, H., Silva, A., Freitas, A. \& Vivaldi, L.J. 2004. Adubação nitrogenada em Capim-Coastcross: efeitos na extração de nutrientes e recuperação aparente do nitrogênio. Revista Brasileira de Zootecnia, 33, 68-78.

Rodrigues, A., Cecato, U., Damasceno, J., Galbeiro, S., Gomes, J. \& Avanzzi, L. 2009. Produção, quantidade e concentração de macronutrientes do material morto de capimmombaça, fertilizado com fontes de fósforo. Arquivo Brasileiro de Medicina Veterinaria e Zootecnia, 61, 445-451.

Salazar, J.A.E. 2004. El nitrógeno en los sistemas ganaderos de leche. Agronomía Mesoamericana, 17, 69-77.

Sangoi, V.L., Ernani, P.R. \& Rampazzo, A.L. 2003. Lixiviação de nitrogênio afetada pela forma de aplicação da uréia e manejo dos restos culturais de aveia em dois solos com texturas contrastantes. Ciência Rural, 33, 6570.

Silva, D.R.G., Costa, K., Faquim, V., Oliveira, I. \& Bernardes, T.F. 2013. Doses e fontes de nitrogênio na recuperação das características estruturais e produtivas do capim-Marandu. Revista Ciência Agronômica, 44, 184-191.

Silva, F. \& Azevedo, C. 2002. Versão do programa computacional Assistat para o sistema operacional Windows. Revista Brasileira de Produtos Agroindustriais, 4, 7178.

Silva, T., Santos, A.d., Santos, J.d.S. \& Silva, J.d. 2005. Produção do capim Marandu submetido a doses de nitrogênio em um Latossolo Amarelo. Agropecuária Técnica (UFPB), 26, 29-35.

Teixeira, F.A., Bonomo, P., Pires, A.J.V., Silva, F., Rosa, R. \& Nascimento, P.V.N. 2011. Diferimento de pastos de Brachiaria decumbens adubados com nitrogênio no início e no final do período das águas. Revista Brasileira de Zootecnia, 40, 1480-1488.

Werner, J.C., Colozza, M.T., Monteiro, F.A. 2001. Adubação de pastagens. In: Simpósio sobre manejo de pastagens, 18., Anais... Piracicaba: Fealq. p. 129-156.

Whitney, A. \& Green, R. 1969. Pangolagrass performance under different levels of nitrogen fertilization in Hawaii. Agronomy Journal, 61, 577-581.

Recebido em Dezembro 10, 2014

Aceito em Maio 27, 2015

License information: This is an open-access article distributed under the terms of the Creative Commons Attribution License, which permits unrestricted use, distribution, and reproduction in any medium, provided the original work is properly cited. 